\title{
Use of Dexmedetomidine for Preventing Pain on Propofol Injection: A Double Blinded Placebo Controlled Study
}

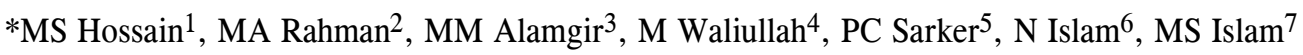

\begin{abstract}
Background and aim of study: Propofol is a commonly used drug for general anesthesia. It can irritate the skin, mucous membrane and venous intima. The main drawback is the pain during intravenous injection. Aim of this prospective randomized study is to observe the efficacy of intravenous dexmedetomidine as pretreatment for the prevention of pain caused by the propofol injection.
\end{abstract}

Methods: A total of 80 adult patients were selected in this study with either sex, ASA (American Society of Anesthesiologists) grade I and II, scheduled for routine elective surgical procedure under general anesthesia. The patients enrolled were divided randomly into two groups of 40 patients each. Group I received $0.25 \mathrm{mcg}$ of intravenous dexmedetomidine in $5 \mathrm{ml}$. Group II (placebo group) received $5 \mathrm{ml}$ of $0.9 \%$ intravenous normal saline one minute before injection of propofol. The patients were asked to report their pain during injection of propofol according to the McCririck and Hunter scale.

Results: The incidence of pain experienced in dexmedetomidine group was $35 \%$ patients and in saline group was $70 \%$ patients $(\mathrm{p}<0.05)$. The severity of POPI was also lower in dexmedetomidine group than the saline group $(\mathrm{p}<0.05)$. The incidence of mild and moderate pain in dexmedetomidine groups versus saline group was $20 \%$ versus $45 \%$ and $15 \%$ versus $25 \%$ respectively $\mathrm{p}<0.05$. There was no severe pain recorded in any groups.

Conclusion: Pretreatment with $0.25 \mathrm{mcg} / \mathrm{kg}$ of dexmedetomidine with venous occlusion for one minute, effectively reduces pain on propofol injection.

Key Words: Dexmedetomidine, propofol, general anesthesia, pain on propofol injection (POPI).

\section{Introduction}

Propofol (2, 6-diisopropylphenol) is a widely used intravenous anesthetic agent to induce general anesthesia. $^{1}$ However, pain following propofol injection is one of the adverse effects of propofol, which occurs in $60 \%$ to $80 \%$ of patients receiving propofol via peripheral vein on the dorsum of hand. $^{2-4}$ Several methods including pretreatment with lignocaine with venous occlusion or premixed lignocaine with propofol have been tried to attenuate pain on propofol injection (POPI). Among these methods, pretreatment with lignocaine with venous occlusion is the most effective method in preventing pain following propofol injection. ${ }^{5,6}$ However, unfortunately this treatment could not abolish the pain. It is reported that the amount of free propofol in the aqueous phase of the emulsion is positively

$1 *$ Dr. Muhammad Sazzad Hossain, Associate Professor and HOD, Department of Anesthesiology, National Institute of ENT, Dhaka, Bangladesh. Mobile: +8801779849059, e-mail: sazzadicu786@yahoo.com

${ }^{2}$ Dr. Md. Afzalur Rahman, Junior Consultant, Department of Anesthesiology, NIENT, Dhaka, Bangladesh

${ }^{3}$ Dr. Md. Mahiuddin Alamgir, Research Officer, Department of Anesthesiology, NIENT, Dhaka, Bangladesh

${ }^{4} \mathrm{Dr}$. Md. Waliullah, Medical Officer, Department of Anesthesiology, NIENT, Dhaka, Bangladesh

${ }^{5}$ Prof. Paresh Chandra Sarker, Department of Anesthesiology, Delta Medical College, Dhaka, Bangladesh

${ }^{6}$ Dr. Nadia Islam, Associate Professor, Pharmacology, Anwer Khan Modern Medical College, Dhaka, Bangladesh

${ }^{7}$ Dr. Md. Sirajul Islam, Assistant Professor, Anesthesiology, Anwer Khan Modern Medical College, Dhaka, Bangladesh

*Corresponding Author

Date of submission: 12.05.2019 Date of acceptance: 20.06.2019

AKMMC J 2019; 10(2) : 164-168 
associated with injection pain. Therefore, propofol long-chain triglycerides (LCT)/medium-chain triglycerides (MCT) was introduced in attempts to prevent injection pain by reducing the concentration of aqueous-free propofol. ${ }^{7}$ However, pain can occur up to $47 \%$ during injection of propofol-LCT/MCT. ${ }^{8}$ It was demonstrated that pretreatment with lignocaine with venous retention before injection of propofol LCT or lignocaine premixed in propofol LCT were more effective in reducing pain than a more expensive reformulation of propofolLCT/MCT. ${ }^{8,9}$ Other studies have suggested methods for controlling POPI, including the injection of low doses of narcotics such as sufentanil and butorphanol, ${ }^{10,11}$ injection in large vessels, cold-warm propofol. ${ }^{12}$ Some researcher used magnesium, ${ }^{13}$ beta blocker, ${ }^{14}$ 5-HT3 receptor antagonists, ${ }^{15}$ Alpha2 agonists like dexmedetomidine $^{16}$ and metoclopramide injection as a premedication for prevention of POPI.

The possible mechanism involved in decreasing propofol injection pain by dexmedetomidine is not fully understood. The possible mechanism might be due to alpha ${ }_{1}$ and alpha $a_{2}$ stimulation causing release of vasodilator prostaglandins that antagonize the vasoconstrictor response. This modulation of the sympathetic response of the venous smooth muscle might be important in endothelial dysfunction causedby propofol. ${ }^{17}$ It may be due to hyperpolarization-activated conductance in the peripherally mediated antinociception, but the peripheral analgesic effects of dexmedetomidine have not yet been fully elucidated. But as dexmedetomidine is more potent alpha ${ }_{2}$ adrenergic agonist compared to clonidine, the peripheral antinociception produced by clonidine-like drugs mediating the local release of enkephalin-like substances is also possible. ${ }^{18,19}$ The present study was conducted to determine the efficacy of intravenous dexmedetomidine $0.25 \mathrm{mcg} / \mathrm{kg}$, in comparison with placebo (normal saline) on incidence and severity of pain on propofol injection (POPI).

\section{Materials \& Methods}

The present double-blind clinical study was conducted on 80 adult patients undergoing elective ENT surgeries in National Institute of ENT, Dhaka during the period of July to October 2018 after receiving informed consent from the patients. The inclusion criteria were ages 20-50 years, Class I and II American Society of Anesthesiology (ASA), no history of known skin disease and severe burns in the organs, lack of diabetes or heart, liver and kidney disorders, no history of known allergy to used drugs, no history of addiction to alcohol and oral or injectable drugs.

The patients were randomly divided into two equal groups of 40 after enrolment in the study. Group I which was scheduled to receive $0.25 \mathrm{mcg} / \mathrm{kg}$ intravenous dexmedetomidine in $5 \mathrm{ml}$ normal saline and Group II which was scheduled to receive $5 \mathrm{ml}$ intravenous normal saline before induction of general anesthesia. On arrival to the operation room, standard monitoring was applied to all patients including pulse oximeter, electrocardiogram and noninvasive arterial blood pressure. A 20-gauge intravenous cannula was placed on the dorsum of non-dominant hand of the patient and Ringer's solution was started. Patients received no premedication. While the venous drainage was occluded by placing an air-filled tourniquet (pressure inflated to $70 \mathrm{~mm} \mathrm{Hg}$ ) on the upper arm by an assistant; a blinded anesthesiologist injected prepared study drug or saline according to the allocation. The occlusion was released after one minute. First one-fourth of induction dose $(2 \mathrm{mg} / \mathrm{kg}$ ) of propofol was injected slowly over 10 seconds. The pain intensity was measured based on McCririck and Hunter scale. ${ }^{20}$ After the assessment of pain, induction of anesthesia was completed with the remaining dose of propofol then tracheal intubation was facilitated with the injection of succinylcholine. Anesthesia was maintained with injection of fentanyl, vecuronium, oxygen, nitrous oxide $(66 \%)$ and halothane. When surgery was completed general anesthesia was reversed as usual.

Grading of pain: As per McCririck and Hunter scale $^{20}$

$$
\begin{aligned}
& 0=\text { No pain } \\
& 1=\text { Mild pain (pain reported only in response to } \\
& \text { questioning without any behavioral signs) } \\
& 2=\text { Moderate pain (pain reported in response to } \\
& \text { questioning and accompanied by a behavioral }
\end{aligned}
$$


MS Hossain, MA Rahman, MM Alamgir et al.

sign or pain reported spontaneously without questioning).

$3=$ Severe pain (strong vocal response or response accompanied by facial grimacing, arm withdrawal or tears).

Statistical analysis: For comparison of quantitative variables between the two groups, the unpaired ttest and for qualitative variables the Chi-squared test was used. The statistically significant level was $\mathrm{P}<0.05$.

\section{Results}

There was no significant demographic difference between the groups (Table I). Basal MAP and HR were comparable in both groups. There were no significant differences of MAP and HR between dexmedetomidine and saline groups during preintubation or three minutes post-intubation period $(p>0.05)$ (Table II). The incidence of pain experienced in dexmedetomidine group (group I) was $35 \%$ patients and in group II (saline group) was $70 \%$ patients, which was statistically significant $\mathrm{p}<0.05$ (Table III). The severity of POPI was also lower in dexmedetomidine group than the saline group $(\mathrm{p}<0.05)$ (Table III). The incidence of mild and moderate pain in groups I versus group II were $20 \%$ versus $45 \%$ and $15 \%$ versus $25 \%$ respectively $\mathrm{p}<0.05$. There was no severe pain recorded in any groups.

Table I: Comparison of demographic data between the two groups

\begin{tabular}{lccc}
\hline & \multicolumn{2}{c}{ Group I } & \multicolumn{2}{c}{ Group II (Saline } & p value \\
Parameters & $\begin{array}{l}\text { (Dexmedetomid- } \\
\text { inegroup) } \mathbf{n}=\mathbf{4 0}\end{array}$ & group) $\mathbf{n}=\mathbf{4 0}$ & \\
\hline $\begin{array}{l}\text { Age in years } \\
\text { (mean } \pm \text { SD) }\end{array}$ & $38.23 \pm 8.12$ & $37.65 \pm 9.32$ & $\mathrm{p}>0.05$ \\
$\begin{array}{l}\text { Weight in kg } \\
\text { (mean } \pm \text { SD) }\end{array}$ & $64.86 \pm 8.72$ & $65.28 \pm 9.36$ & $\mathrm{p}>0.05$ \\
Sex (male/female) & $36 / 4$ & $26 / 14$ & $\mathrm{p}>0.05$ \\
ASA Physical status I/II & & $37 / 3$ & $\mathrm{p}>0.05$ \\
& & & \\
& & & \\
\hline
\end{tabular}

Table II: Changes of mean arterial pressure and heart rate between two groups

\begin{tabular}{lccc}
\hline $\begin{array}{l}\text { Hemodynamic } \\
\text { parameter }\end{array}$ & $\begin{array}{c}\text { Basal } \\
\text { Group I/Group II }\end{array}$ & $\begin{array}{c}\text { Pre intubation } \\
\text { Group I/Group II }\end{array}$ & $\begin{array}{c}\text { Post intubation } \\
\text { Group I/Group II }\end{array}$ \\
\hline $\begin{array}{l}\text { Mean arterial pressure } \\
\text { (MAP) mm Hg }\end{array}$ & $94 / 97$ & $90 / 92$ & $105 / 108$ \\
Heart rate per minute & $78 / 81$ & $73 / 77$ & $91 / 93$ \\
\hline
\end{tabular}

Table III: Incidence and severity of pain following propofol injection between two groups

\begin{tabular}{lccc}
\hline Characteristics of pain & $\begin{array}{c}\text { Group I } \\
\text { (Dexmedetomidine } \\
\text { group) n=40 } \\
\text { Number and \% }\end{array}$ & $\begin{array}{c}\text { Group II (Saline } \\
\text { group) } \mathbf{n = 4 0}\end{array}$ & p value \\
Number and \% & \\
\hline No pain & $26(65 \%)$ & $12(30 \%)$ & $\mathrm{p}<0.05$ \\
Pain & $14(35 \%)$ & $28(70 \%)$ & $\mathrm{p}<0.05$ \\
Mild pain & $8(20 \%)$ & $18(45 \%)$ & $\mathrm{p}<0.05$ \\
Moderate pain & $6(15 \%)$ & $10(25 \%)$ & $\mathrm{p}<0.05$ \\
Severe pain & 0 & 0 & - \\
\hline
\end{tabular}

\section{Discussion}

Propofol, an excellent IV anesthetic belonging to the phenol group, can irritate the skin, the mucous membrane and the venous intima. The mechanism of pain is attributed to the activation of the kininkallikrein system that releases bradykinin, causing vasodilatation and hyper-permeability, thereby increasing contact between the aqueous phase propofol and the free nerve endings. A number of drugs were tried for attenuation of propofol injection pain.

In the present study, the overall incidence and severity of pain were significantly less in dexmeditomidine group compared to placebo group. The incidence of pain experienced in dexmedetomidine group (group I) was $35 \%$ patients and in group II (saline group) was $70 \%$ patients $(p<0.05)$. The severity of POPI was also lower in dexmedetomidine group than the saline group $(\mathrm{p}<0.05)$. The incidence of mild and moderate pain in groups I versus group II were $20 \%$ versus $45 \%$ and $15 \%$ versus $25 \%$ respectively $\mathrm{p}<0.05$. There was no severe pain recorded in any groups. The study done by Singh et al. ${ }^{21}$ in alleviating propofol 
injection pain using $0.25 \mathrm{mcg} / \mathrm{kg}$ of dexmedetomidine and $0.5 \mathrm{mg} / \mathrm{kg}$ lignocaine and recorded POPI in $37.14 \%$ and $20 \%$ patients respectively. Debnath et $a .^{22}$ had a comparative study of effects of dexmedetomidine and lignocaine in alleviating propfol injection pain in a tertiary care center, their result showed $34 \%$ patients experienced pain on propofol injection. Another study on attenuation of POPI by Turan et al. ${ }^{23}$ comparing the effect of dexmedetomidine and lignocaine and found $33.34 \%$ complained pain during propofol injection in dexmedetomidine group. Uzan et al. ${ }^{18}$ also had a study on prevention of POPI using dexmedetomidine and pain recorded $43 \%$ patients during injection of propofol. The result of present study is nearly similar to the above studies except that of Uzan et al. ${ }^{18}$ which is a bit higher.

\section{Conclusion}

Pretreatment with a dose of $0.25 \mathrm{mcg} / \mathrm{kg}$ dexmedetomidine intravenously administered with mid-arm occlusion applied for one minute before propofol administration can effectively reduce the incidence and severity of pain on propofol injection.

\section{Conflict of interest: None.}

\section{References}

1. Dundee JW. New i.v. anaesthetics. Br J Anaesth 1979; 51: 641-8.

2. Nathanson MH, Gajraj NM, Russell JA. Prevention of pain on injection of propofol: a comparison of lidocaine with alfentanil. Anesth Analg 1996; 82: 469-71.

3. Tan $\mathrm{CH}$, Onsiong MK. Pain on injection of propofol. Anaesthesia 1998; 53: 468-76.

4. Agarwal A, Ansari MF, Gupta D, et al. Pretreatment with thiopental for prevention of pain associated with propofol injection. Anesth Analg 2004; 98: 683-6.

5. King SY, Davis FM, Wells JE, et al. Lidocaine for the prevention of pain due to injection of propofol. Anesth Analg 1992; 74: 246-9.
6. Picard $\mathrm{P}$, Tramèr MR. Prevention of pain on injection with propofol: a quantitative systematic review. Anesth Analg 2000; 90: 963-9.

7. Babi J, Doenicke V, Monch V. New formula of propofol in an LCT/MCT emulsion: approach to reduce pain on injection. Eur Hosp Pharm 1995; 1: 15-21.

8. Schaub E, Kern C, Landau R. Pain on injection: a double-blind comparison of propofol with lidocaine pretreatment versus propofol formulated with long-and medium-chain triglycerides. Anes and Analg 2004; 99: 1699-702.

9. Adam S, van Bommel J, Pelka $\mathrm{M}$, et al. Propofol-induced injection pain: comparison of a modified propofol emulsion to standard propofol with premixed lidocaine. Anesth Analg 2004; 99: 1076-9.

10. Ghai B, Makkar JK, Bala I, Wig J. Effect of parecoxib pretreatment and venous occlusion on propofol injection pain: a prospective, randomized, double-blinded, placebo-controlled study. J Clin Anesth. 2010; 22(2): 88-92.

11. Agarwal A, Raza M, Dhiraaj S, et al. Pain during injection of propofol: the effect of prior administration of butorphanol. Anesth Analg. 2004; 99(1): 117-9.

12. Jeong M, Yoon $\mathrm{H}$. Comparison of the effects of lidocaine pre-administration and local warming of the intravenous access site on propofol injection pain: Randomized, double-blind controlled trial. Int J Nurs Stud. 2016; 61: 209-18.

13. Sun J, Zhou R, Lin $\mathrm{W}$, et al. Magnesium Sulfate Plus Lidocaine Reduces Propofol Injection Pain: A Double-blind, Randomized Study. Clin Ther. 2016; 38(1): 31-8.

14. Salman EA, Titiz L, Akpek E, et al. Pretreatment with a very low dose of intravenous esmolol reduces propofol injection pain. Agri. 2013; 25(1): 8-13.

15. Wang W, Zhou L, Wu L-X, et al. 5-HT3 receptor antagonists for propofol injection pain: A meta-analysis of randomized controlled trials. Clin Drug Investig. 2016; 36(4): 243-53. 
16. Sarkilar G, Kara I, Duman A, et al. Effect of dexmedetomidine on pain caused by injection of propofol. Nobel Med 2012; 8: 83-8.

17. Callow ID, Campisi P, Lambert ML, et al. Arnold JM. Enhanced in vivo alpha1- and alpha 2 -adrenoceptor-mediated vasoconstriction with indomethacin in humans. Am J Physiol 1998; 275: H837-43.

18. Uzun S, Karagoz HA, Kose AE, et al. Dexmedetomidine for prevention of propofol injection pain. Anaesthesiol Clin Pharmacol 2008; 24: 406-8.

19. Dalle C, Schneider M, Clergue $\mathrm{F}$, et al. Inhibition of the $\mathrm{I}(\mathrm{h})$ current in isolated peripheral nerve: A novel mode of peripheral antinociception. Muscle Nerve 2001; 24: 254-61.
20. McCrirrick A, Hunter S. Pain on injection of propofol: the effect of injectated temperature. Anaesthesia 1990; 45: 443-4.

21. Singh HS, Singh LD, Singh NR, et al. Effects of dexmedetomidine and lidocaine in alleviating propofol injection pain: A randomized controlled trial. J Med Soc 2015; 29: 31-4.

22. Debnath J, Chakrabarti A. A Comparative study of effects of dexmedetomidine and lidocaine in alleviating propofol injection pain in a tertiary care centre. Ind J App Res 2017; 8: 363-4.

23. Turan A, Memis D, Kaya $\mathrm{G}$, et al. The prevention of pain from injection of propofol by dexmedetomidine and comparison with lidocaine. Can J Anaesth 2005; 52: 548-9. 